\title{
Synthesis and pharmacological profile of some new 2-substituted-2, 3-dihydro-1H-perimidine
}

\begin{tabular}{ccc}
\hline Kezhal M. Salih $^{1}$ & Dana Ameen $^{1 *}$ & Aras Najmaddin Hamad $^{1}$ \\
\hline Abstract
\end{tabular}

Background and objective: The development of new antimicrobial drugs is still demanded as there is increasing resistance of microorganisms to currently available antimicrobial drugs and searches for safer nonsteroidal anti-inflammatory agents with greater cyclooxygenase COX II selectivity is challenging. The new series of 2-substituted2,3-dihydro- $1 \mathrm{H}$-perimidine (4a-j) that are close analogs to Naproxen 5, might inhibit COX II enzyme in a similar manner to naproxen 5. This study aimed to synthesize some new heterocyclic compounds for enhancing biological activity.

Methods: 1,8-Diaminonaphthalene 2 was condensed with a variety of aldehydes and ketones 3 to afford a new series of 2-substituted-2,3-dihydro-1H-perimidines4a-j using a suitable synthetic strategy. All the synthesized 2,3-dihydro-1 $\mathrm{H}$-perimidine compounds 4a-jwere screened for their invitro antimicrobial activities against two identifiable strains using the agar diffusion method. At the same time, the synthesized pyrimidine derivatives 4a-were evaluated for their COX inhibition activity. Supplementary to these, the constitutions of the newly synthesized 2,3-dihydro- $1 \mathrm{H}$-perimidines $4 \mathrm{a}$-j had been confirmed on the basis of their IR, ${ }^{1} \mathrm{H}$ - and ${ }^{13} \mathrm{C}-\mathrm{NMR}$ spectral data.

Results: The synthesized 2-substituted-2,3-dihydro-1H-perimidine compounds 4a-j exhibited promising antibacterial activity against Escherichia coli microorganism, while none of the synthesized derivatives 4a-jshowed likely result against Staphylococcus aureus strain. In addition, compound $4 \mathrm{~b}$ had the most potent anti-inflammatory activity with an inhibition rate of $47 \%$ at $1000 \mathrm{nM}$.

Conclusion: The synthesized products4a-j possessed antibacterial activity (towards Escherichia coli microorganism; however, compounds $4 \mathrm{c}, 4 \mathrm{e}$, and $4 \mathrm{j}$ took the highest activity) and anti-inflammatory activity (compound $4 \mathrm{~b}$ showed the highest inhibition rate).

Keywords: 1,8-diaminonaphthalene; Carbonyl compounds; Dipolar cyclisation; 2,3-dihyroperimidin; Antibacterial.

\section{Introduction}

One of the most interesting compounds in our daily life is heterocyclic compounds. Heterocyclic compounds containing one or more hetero atoms. Having a wide range of application such as used as pharmaceuticals, as agrochemicals and a $\mathrm{s}$ veterinary products. ${ }^{1-3}$ In addition, they have applications as sanitizers, developers, antioxidants, as corrosion inhibitors, as copolymers, dye stuff. Importantly, few antibiotics such as penicillin, cephalosporin have heterocyclic moiety. ${ }^{4}$ Moreover, perimidine-2-thiol derivatives and their ligands $\left(\mathrm{C}_{24} \mathrm{H}_{14} \mathrm{~N}_{4} \mathrm{~S}_{2} \mathrm{O}_{2}\right) \quad \mathrm{H} 2 \mathrm{~L} 1$ and $\left(\mathrm{C}_{26} \mathrm{H}_{18} \mathrm{~N}_{4} \mathrm{~S}_{2} \mathrm{O}_{2}\right)$ H2L2 had been documented with transition metal ions, such as Copper (II), Silver (I), Cobalt (II) and Ruthenium (III) for their antimicrobial, analgesic and anti-inflammatory activities. ${ }^{5}$ On the other hand, the development of novel antimicrobial drugs is still in demand as there is increasing resistance of microorganisms to the currently available antimicrobial drug. ${ }^{6}$ Among the heterocyclic compounds, such as

${ }^{1}$ Department of Pharmaceutical Chemistry, College of Pharmacy, Hawler Medical University, Erbil, Iraq.

${ }^{2}$ Department of Pharmacognosy, College of Pharmacy, Hawler Medical University, Erbil, Iraq.

* Correspondence: dana.ameen@hmu.edu.krd 
perimidine derivatives are of wide interest because they exhibit a diverse range of biological activities (Figure 1). ${ }^{7}$ The derivatives of perimidine described as DNA-intercalating antitumor agents against the carcinogenic line. , $^{8,9}$-Dihydro-1 $\mathrm{H}$-perimidine 1 is a saturated form of perimidine at 2 and 3 position which is a synthetic tricyclic compounds including two nitrogen atom. ${ }^{10}$ Several preparative methods for the synthesis of perimidine derivatives have been documented. ${ }^{11}$ Cyclisation reaction is one of the most important reactions of imines for the preparation of different heterocyclic compounds. ${ }^{12}$ Interestingly, one of the major targets for curing bacterial infection is the cell wall of bacteria. The cell wall synthesis inhibited by ß-lactams, such as penicillins and cephalosporins, which inhibit peptidoglycan polymerization, and by vancomycin, which combines with cell wall substrates. ${ }^{13}$ Polymyxins disrupt the plasma membrane, causing leakage. ${ }^{14}$ Accordingly, the synthesis, the spectral data, and the biological studies of the new compounds $4 a-j$ were achieved. The antibacterial activity of the new synthesized compounds was against gram-positive bacteria Staphylococcus aureus and gram-negative bacteria Escherichia coli. This study aimed to synthesize some new heterocyclic compounds for enhancing biological activity.

\section{Methods}

This experimental study was designed to evaluate newly synthesized perimidine derivatives through the condensation of 1,8-diaminonaphthalene 2 with the corresponding aldehydes and ketones 3 to afford the 2-substituted-2,3-dihydro-1 $\mathrm{H}$ perimidines4a-j using a suitable synthetic strategy, as illustrated in Scheme 1. All the synthetic procedures were held at Hawler Medical University, College of Pharmacy, Pharmaceutical and Organic Chemistry Lab. between $8^{\text {th }}$ of April 2015 to $1^{\text {st }}$ of October 2016. Then after, the synthesized perimidine derivatives should fully characterized and tested for their antibacterial and anti-inflammatory activities.

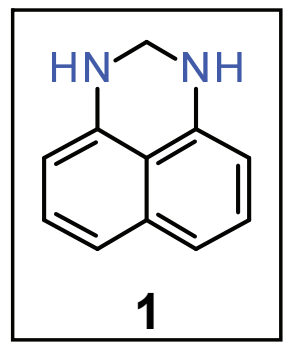

Figure 1: Structure of perimidine.

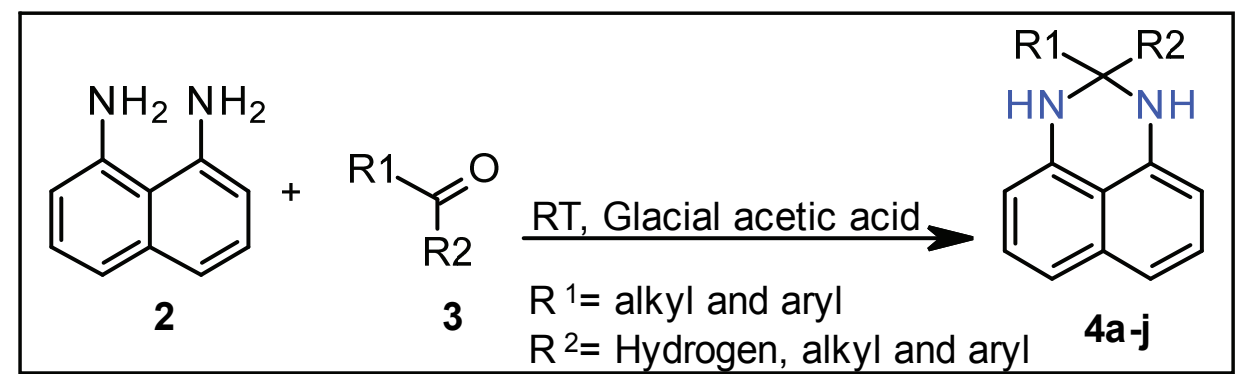

Scheme 1: Synthesis of 2-substituted-2,3-dihydro-1 $H$-perimidine (4a-j) 
The melting points of the synthesized compounds were determined on a Gallen Kamp electrothermal apparatus by the open capillary method and are uncorrected. IR spectra were recorded on a ThermoMattson-300 Spectrophotometer and Bio-Rad Merlin, as $\mathrm{KBr}$ disc (Chemistry Department, College of Science, Salahaddin University/Erbil). ${ }^{1} \mathrm{H}$ - and ${ }^{13} \mathrm{C}$ NMR spectrum were measured using a Bruker ultra shield $300 \mathrm{MHz}$ with internal TMS (Central Lab., Jordan University of Science and Technology, Jordan); chemical shifts are given in ppm. Then after, the synthesized 2,3-dihydro-1Hperimidine compounds 4a-jwere screened for their invitro antimicrobial activities against two identifiable strains using agar diffusion method at Hawler Medical University, College of Pharmacy, Microbiological Lab. Additionally, the synthesized perimidine derivatives 4a-jwere evaluated for their COX inhibition activity at Central University of Lancashire, School of Pharmacy and Biomedical Sciences, UK.

Synthesis of 2-substituted-2,3-dihydro$1 \mathrm{H}$-perimidine $4 \mathrm{a}-\mathrm{j}$

A mixture of 1,8-diaminonaphthalene 2 (1.582 g, 0.01 mole) and appropriate aldehyde and ketones 3(0.01 mole) in 10 $\mathrm{mL}$ of absolute ethanol and in the presence of a few drops of glacial acetic acid was stirred for about 40-48 hours at room temperature (the progress of the reaction was monitored by TLC). ${ }^{15}$ After completion of the reaction, the reaction mixture was cooled down, and then the solid that separated out was filtered off, dried and re-crystallized from appropriate solvent. ${ }^{16}$

\section{Biological study}

General procedure for the COX inhibitor screening assay

The COX activity assay carried out here was Cayman's COX fluorescent inhibitor screening assay which uses a convenient fluorescence-based method for screening both bovine COXI and human recombinant COX II for isozyme-specific inhibitors. ${ }^{17}$

$1-100 \%$ initial activity wells: added $150 \mu \mathrm{l}$ of assay buffer, $10 \mu \mathrm{l}$ of heme, $10 \mu \mathrm{l}$ of ADHP (10-acetyl-3,7dihyroxyphenoxazepine), $10 \mu \mathrm{l}$ of enzyme (either COX I or COX II), and $10 \mu \mathrm{l}$ of DMSO.

2- Background wells: added $160 \mu \mathrm{l}$ of assay buffer, $10 \mu \mathrm{l}$ of heme, $10 \mu \mathrm{l}$ of $\mathrm{ADPH}$, and $10 \mu \mathrm{l}$ of DMSO.

3- Inhibitor wells: added $150 \mu$ l of assay buffer, $10 \mu$ l of heme, $10 \mu$ l ADPH, 10 $\mu \mathrm{l}$ of enzyme (either COX I or COX II), and $10 \mu \mathrm{l}$ of inhibitors*.

4- The reactions were initiated by quickly adding $10 \mu \mathrm{l}$ of arachidonic acid solution to all the wells being used.

5- The wells were incubated for two minutes at room temperature.

6 - The plate was read using an excitation wavelength between 530-540 nm and an emission wavelength between 585$595 \mathrm{~nm}$.

7- The average fluorescence of each sample was determined.

8- The fluorescence of the background wells was subtracted from the fluorescence of the $100 \%$ initial activity and the inhibitor wells.

9- The percent inhibition was determined for each sample by subtracting each inhibitor sample value from the $100 \%$ initial activity sample value, the result divide by the $100 \%$ initial activity value and then multiplied by 100 to give the percent inhibition.

*Inhibitor (compounds 4a-j) solutions were prepared in a concentration of 10,100 and $1000 \mathrm{~nm}$ using DMSO as a solvent. ${ }^{17}$

\section{Antibacterial Activity}

The sensitivity of 2-substituted-2,3-dihydro$1 \mathrm{H}$-perimidine $(4 \mathrm{a}-\mathrm{j})$ was carried out against two kinds of bacteria, gram-positive $S$. aureus and gram-negative bacteria $E$. coli using disc agar diffusion method. The tests were performed using Muller Hinton agar. The medium was prepared using nutrient agar for the preservation of pure culture, then sterilized by autoclave, and poured in Petri dish to a depth of $4 \mathrm{~mm}$. Activation of each type of bacteria gram-positive (S. aureus) and 
Gram-negative (E. coli) was done before culturing on the nutrient agar in a nutrient broth, which was used for dilution of bacterial and cultivation of culture isolates for 24 hours in $37^{\circ} \mathrm{C}$, then inoculation of the plates. The discs of the synthesized compounds were prepared by mixing a compound with $\mathrm{KBr}$ powder (1:3). The mixture was pressed under pressure $\mathrm{KBr}$ which has been used as a blank disc. The dried surface of the Muller Hinton agar plate was streaked; tow dried discs were placed on the surface of the cultured media per petri dish. The plates were then incubated at $37^{\circ} \mathrm{C}$ for 18 to 24 hours and then after the inhibition zone were manually measured in $\mathrm{mm}$.

\section{Statistical Analysis}

All data are expressed as mean $\pm S D$ of triplicate experiments.

\section{Results}

The structure of the obtained new 2,3-dihydro- $1 \mathrm{H}$-perimidines $(4 \mathrm{a}-\mathrm{j})$ was elucidated by various spectroscopic techniques. The infrared as well as ${ }^{1} \mathrm{H}$ - and ${ }^{13} \mathrm{C}-\mathrm{NMR}$ spectral data of some synthesized compounds are consistent with the expected structures. For example, the infrared spectrum of 2,2-dibenzyl-2,3dihydro- $1 H$-perimidine $4 \mathrm{~h}$ which is shown Table 1, revealed the most important features of the dipolar cyclisation of 1,8diaminonaphthalene2 with the carbonyl carbon atom of the carbonyl compounds 3by exhibiting a medium and a diagnostic sharp peak at3329 to $3396 \mathrm{~cm}^{-1}$ due to $\mathrm{NH}$ stretching vibration and disappearance of four bands belong to two $\mathrm{NH}_{2}$ stretching vibration in IR spectra at $3412,3386,3332$, $3304 \mathrm{~cm}^{-1}$ of 1,8-diaminonaphthalene. The first evidence for the synthesis of the new compounds comes from the physical properties for example the melting point and color which compared with the starting materials. The reaction product were solid obtained with high yields as shown in Table 1

Table 1: Some physical constants and the diagnostic stretching band for $\mathrm{NH}$ moiety in IR absorption of perimidine compounds $4 a-j$

\begin{tabular}{clcccc}
\hline Entry & Carbonyl comp. & MP ${ }^{\circ} \mathbf{C}$ & Color & $\%$ Yield & NH Str. \\
\hline $\mathbf{4 a}$ & Cinnamaldehyde & $172-174$ & Pink & 85 & 3387 \\
$\mathbf{4 b}$ & 2-chlorobenzaldehyde & $200-202$ & Colorless & 81 & 3396 \\
$\mathbf{4 c}$ & 2-hydroxybenzaldehyde & $159-161$ & Pink & 84 & 3338 \\
$\mathbf{4 d}$ & 3,4-dihydroxybenzaldehyde & $186-188$ & Yellow & 80 & 3329 \\
$\mathbf{4 e}$ & Furfural & $166-168$ & Red & 84 & 3368 \\
$\mathbf{4 f}$ & ethyl methyl ketone & $157-159$ & Yellow & 53 & 3381 \\
$\mathbf{4 g}$ & 1,1-dimethoxy-3-butanone & $178-180$ & Pink & 85 & 3338 \\
$\mathbf{4 h}$ & Dibenzylketone & $239-241$ & Brown & 90 & 3373 \\
$\mathbf{4 i}$ & 3,4-dimethoxyacetophenone & $120-122$ & Orange & 95 & 3368 \\
$\mathbf{4 j}$ & 4-nitroacetophenone & $160-162$ & Brown & 92 & 3361 \\
\hline
\end{tabular}


The structure of 2-(substituted phenyl )-2,3 -dihydro- $1 \mathrm{H}$-Perimidine was indicated from the ${ }^{1} \mathrm{H}-\mathrm{NMR}$ spectra Table 2 by observation of one proton at $\delta 5.2 \mathrm{ppm}$ due to single $\mathrm{C}-\mathrm{H}$ proton. In addition, the appearance of multiplet signals at $\delta 6.4$ to $8 \mathrm{ppm}$ for ten protons belongs to phenyl and naphthyl rings which supported the formation of the desired product. The formation of compounds $(4 \mathrm{~g}),(4 \mathrm{i})$ and $(4 \mathrm{j})$ established from the ${ }^{1} \mathrm{H}-\mathrm{NMR}$ spectra through the appearance of signals at $\delta 1.5,1.78,1.8$, $3.1,3.9 \mathrm{ppm}$ attributed to $\mathrm{CH}_{3}$ and $\mathrm{OCH}_{3}$ protons respectively. The singlet signal belongs to two $\mathrm{N}-\mathrm{H}$ of perimidine moiety seen between 4.2 to $6.5 \mathrm{ppm}$, also the spectra of compounds $4 \mathrm{~g}$ and $4 \mathrm{~h}$ showed $\mathrm{CH}_{2}$ group as a doublet at $\delta 2.05$ and
$2.99 \mathrm{ppm}$ (Table 2). The structure of the products were established from ${ }^{13} \mathrm{C}-\mathrm{NMR}$ spectra, such as observation ofa line due to C-HNcarbon at $\delta$ (63.5 to76) ppm for all the synthesized compounds, and lines attributed to aromatic regionfor phenyl and naphthyl ringsatठ (105- 154) ppm which were recorded as 10 lines in ${ }^{13} \mathrm{C}$ - NMR spectrum for compound (4j) and 12 linesfor compounds (4b and 4i). Spectra of compounds $(4 \mathrm{~g})$ and $(4 \mathrm{i})$ were showed another evidence which was a line for $\mathrm{OCH}_{3}$ carbon at $\delta 53,08$ and $56.01 \mathrm{ppm}$, while the appearance of a lineat $\delta 43.23$ and $44 \mathrm{ppm}$ related to $\mathrm{CH}_{2}$ carbon were supported the formation of compounds $4 \mathrm{~g}$ and $4 \mathrm{~h}$, the methyl carbon was observed atס 26.82,28.19.30.38 ppm (Table 3).

Table 2: Diagnostic peaks in ${ }^{1} \mathrm{H}-\mathrm{NMR}$ spectra for some synthesized2-substituted-2,3dihydro- $1 \mathrm{H}$-perimidine(4a, $4 \mathrm{~b}, 4 \mathrm{~g}, 4 \mathrm{~h}, 4 \mathrm{i}$ and $4 \mathrm{j}$ ), where the solvent was $\mathrm{CDCl}_{3}$.

\begin{tabular}{lccccccc}
\hline Compound & $\begin{array}{c}\mathbf{N}-\mathbf{H}(\mathbf{s}) \\
\mathbf{p p m}\end{array}$ & $\begin{array}{c}\mathbf{C}-\mathrm{H}(\mathbf{m}) \\
\text { (aromatic)ppm }\end{array}$ & $\mathbf{O C H}_{3}(\mathbf{s})$ & $\begin{array}{c}\mathbf{C}-\mathrm{H}(\mathbf{s}) \\
\mathbf{p p m}\end{array}$ & $\mathbf{C H}=\mathrm{CH}-\mathrm{Ar}$ & $\begin{array}{c}\mathrm{CH}_{2}(\mathbf{d}) \\
\mathbf{p p m}\end{array}$ & $\begin{array}{c}\mathrm{CH}_{3}(\mathbf{s}) \\
\mathbf{P p m}\end{array}$ \\
\hline $\mathbf{4 a}$ & 6.42 & $\begin{array}{c}7.45-7 \\
(11 \mathrm{H})\end{array}$ & & 6.5 & $\begin{array}{c}\text { Mixed within } \\
\text { aromatic region }\end{array}$ & & \\
$\mathbf{4 b}$ & 4.3 & $6.5-7.7(10 \mathrm{H})$ & & 5.2 & & & \\
$\mathbf{4 g}$ & 4.5 & $6.4-7.2(6 \mathrm{H})$ & 3.1 & 4.7 & & 2.05 & 1.5 \\
$\mathbf{4 h}$ & 4.2 & $6.4-7.5(16 \mathrm{H})$ & & & & 2.99 & \\
$\mathbf{4 i}$ & 4.5 & $6.4-7.5(6 \mathrm{H})$ & 3.9 & & & & 1.78 \\
$\mathbf{4 j}$ & 6.5 & $7-8(10 \mathrm{H})$ & & & & & 1.8 \\
\hline
\end{tabular}

Table 3: Diagnostic peaks in ${ }^{13} \mathrm{C}-\mathrm{NMR}$ spectra for some synthesized 2-(substituted)-2, 3-dihydro-1H-perimidine (4a, 4b, 4g, 4h, $4 \mathrm{i}$ and $4 \mathrm{j})$, where the solvent was $\mathrm{CDCl}_{3}$.

\begin{tabular}{|c|c|c|c|c|c|c|c|}
\hline Compounds & $\mathrm{C}(\mathrm{Ar})$ & $\mathrm{C}-\mathrm{H}$ & C-NH & $\mathrm{OCH}_{3}$ & $\mathrm{CH}_{2}$ & $C=C$ & $\mathrm{CH}_{3}$ \\
\hline $4 a$ & $108-140.35$ & & 76 & & & $\begin{array}{l}\text { Mixed within } \\
\text { aromatic region }\end{array}$ & \\
\hline $4 b$ & $105-141$ & & 63.52 & & & & \\
\hline $4 \mathrm{~g}$ & $106-140$ & 102.9 & 65.25 & 53.08 & 43.29 & & 26.82 \\
\hline $4 h$ & $106.4-139.73$ & & 68.1 & & 44 & & \\
\hline $4 i$ & $106-148.97$ & & 68.04 & 56.01 & & & 28.19 \\
\hline $4 j$ & $107-154$ & & 68.1 & & & & 30.38 \\
\hline
\end{tabular}


Microbial growth inhibition were indicated by measuring the diameter of the zone of inhibition (using disk agar diffusion method) and the results were represented in Table 4. All the synthesized used compounds were tested for their antibacterial activity against both bacteria $S$. aureus and E. coli. The synthesized compounds were more active against $E$. coli than the $S$. aureus. The most effective compounds of perimidine derivatives were
$4 \mathrm{a}, 4 \mathrm{c}, 4 \mathrm{e}$, and $4 \mathrm{j}$,while other compounds (4b, 4d, 4f, 4g, 4h and 4i) were showed moderate activity against $E$. coli. The percentage of the sensitivity of the bacteria species under the study were investigated against $S$. aureus and $E$. coli, sensitivity of $S$. aureus against the synthesized compounds was $0 \%$ it means that $100 \%$ resisted where as the E. coli showed $100 \%$ sensitivity and $0 \%$ resistance against the new compounds as shown in Table 5.

Table 4: Antibacterial activity of the synthesized 2-(substituted)-2,3-dihydro-1H-perimidine (4a-j) against S. aureus (ATCC 25923) and E. coli (ATCC 35218).

\begin{tabular}{lcc}
\hline Compounds & $\begin{array}{c}\text { S. aureus } \\
\text { ATCC } 25923\end{array}$ & E. coli \\
& ATCC 35218 \\
\hline $4 \mathrm{a}$ & ++ & ++++ \\
$4 \mathrm{~b}$ & ++ & +++ \\
$4 \mathrm{c}$ & ++ & ++++ \\
$4 \mathrm{~d}$ & ++ & +++ \\
$4 \mathrm{e}$ & ++ & ++++ \\
$4 \mathrm{f}$ & ++ & +++ \\
$4 \mathrm{~g}$ & ++ & +++ \\
$4 \mathrm{~h}$ & ++ & +++ \\
$4 \mathrm{i}$ & ++ & +++ \\
$4 \mathrm{j}$ & ++ & ++++ \\
\hline
\end{tabular}

Zone of inhibition after $24 \mathrm{hrs}$, zone size: $10-20 \mathrm{~mm}=++; 21-35 \mathrm{~mm}=+++$; $36-50 \mathrm{~mm}=++++$

Table 5: The percentage of the active compounds against S.aureus and E. coli susceptibility.

\begin{tabular}{lcc}
\hline Types of bacteria & Sensitive (\%) & Resistance (\%) \\
\hline S. aureus & 0 & 100 \\
E. coli & 100 & 0 \\
\hline
\end{tabular}




\section{COX inhibition activity}

The COX inhibitory activity assay was carried out by applying the in vitro Cayman's COX fluorescent inhibitor screening protocol in which the inhibitors were tested against both bovine COX I Table 6 and human recombinant COX II Table $7 .^{17}$

Table 6: In vitro bovine COX I assay results.

\begin{tabular}{lcccccc}
\hline \multirow{2}{*}{ Compounds } & $\mathbf{F}$ & $\mathbf{1 0} \mathbf{~ n M}$ & $\mathbf{F}$ & $\mathbf{1 0 0} \mathbf{~ M}$ & $\mathbf{F}$ & $\mathbf{1 0 0 0} \mathbf{n M}$ \\
\hline Naproxen & $23885 \pm 363$ & 37 & $17451 \pm 378$ & 54 & $4752 \pm 279$ & 88 \\
$\mathbf{4 a}$ & $24005 \pm 274$ & 37 & $23119 \pm 251$ & 39 & $22842 \pm 218$ & 40 \\
$\mathbf{4 b}$ & $29188 \pm 666$ & 23 & $27533 \pm 445$ & 27 & $26992 \pm 234$ & 29 \\
$\mathbf{4 c}$ & $27149 \pm 612$ & 28 & $26600 \pm 184$ & 30 & $23262 \pm 265$ & 39 \\
$\mathbf{4 d}$ & $33824 \pm 567$ & 11 & $25696 \pm 408$ & 33 & $23082 \pm 53$ & 40 \\
$\mathbf{4 e}$ & $31611 \pm 404$ & 17 & $27504 \pm 499$ & 28 & $24246 \pm 160$ & 37 \\
$\mathbf{4 f}$ & $28412 \pm 258$ & 26 & $27192 \pm 112$ & 29 & $24936 \pm 325$ & 35 \\
$\mathbf{4 g}$ & $29819 \pm 625$ & 22 & $28600 \pm 407$ & 25 & $25838 \pm 169$ & 32 \\
$\mathbf{4 h}$ & $33621 \pm 444$ & 12 & $25692 \pm 213$ & 33 & $22826 \pm 160$ & 41 \\
$\mathbf{4 i}$ & $33311 \pm 240$ & 13 & $29052 \pm 234$ & 24 & $25245 \pm 116$ & 34 \\
$\mathbf{4 j}$ & $32251 \pm 105$ & 16 & $30296 \pm 501$ & 21 & $26851 \pm 79$ & 30 \\
\hline
\end{tabular}

$\mathrm{F}=$ Mean $\pm \mathrm{SD}$ of the initial fluorescence activity. $\mathrm{nM}=$ Nano-molar concentrations of the synthesized perimidine derivatives $4 a-j$.

Table 7: In vitro human recombinant COX II assay results.

\begin{tabular}{lcccccc}
\hline \multirow{2}{*}{ Compounds } & $\mathbf{F}$ & $\mathbf{1 0} \mathbf{~ n M}$ & $\mathbf{F}$ & $\mathbf{1 0 0} \mathbf{~ n ~}$ & $\mathbf{F}$ & $\mathbf{1 0 0 0} \mathbf{~ M}$ \\
\hline Naproxen & $27310 \pm 246$ & 31 & $26424 \pm 329$ & 33 & $13530 \pm 528$ & 66 \\
$\mathbf{4 a}$ & $27047 \pm 437$ & 32 & $26625 \pm 461$ & 33 & $23780 \pm 408$ & 40 \\
$\mathbf{4 b}$ & $24931 \pm 459$ & 37 & $22437 \pm 697$ & 44 & $21063 \pm 680$ & 47 \\
$\mathbf{4 c}$ & $30500 \pm 441$ & 23 & $26859 \pm 899$ & 32 & $24297 \pm 61$ & 39 \\
$\mathbf{4 d}$ & $29506 \pm 597$ & 22 & $25489 \pm 572$ & 33 & $22863 \pm 528$ & 40 \\
$\mathbf{4 e}$ & $27556 \pm 386$ & 27 & $27293 \pm 664$ & 28 & $23987 \pm 266$ & 37 \\
$\mathbf{4 f}$ & $28099 \pm 21$ & 26 & $26725 \pm 208$ & 29 & $24729 \pm 292$ & 35 \\
$\mathbf{4 g}$ & $29482 \pm 335$ & 22 & $24859 \pm 415$ & 35 & $22252 \pm 253$ & 42 \\
$\mathbf{4 h}$ & $29515 \pm 584$ & 22 & $25410 \pm 325$ & 33 & $22325 \pm 218$ & 41 \\
$\mathbf{4 i}$ & $29167 \pm 444$ & 23 & $25670 \pm 347$ & 32 & $21229 \pm 81$ & 44 \\
$\mathbf{4 j}$ & $28158 \pm 63$ & 26 & $26725 \pm 208$ & 31 & $24557 \pm 287$ & 35 \\
\hline
\end{tabular}

$\mathrm{F}=$ Mean $\pm \mathrm{SD}$ of the initial fluorescence activity. $\mathrm{nM}=$ Nano-molar concentrations of the synthesized perimidine derivatives $4 a-j$. 


\section{Discussion}

The impartial of this study was to synthesize, characterize, and evaluate the antibacterial activity of some new 2-(substituted)-2, 3dihydro- $1 \mathrm{H}$-perimidines 4a-j. Preparation of 2,3-dihydro-1 $\mathrm{H}$ perimidine from the reaction of 1,8diaminonaphthalene 2 with various carbonyl compounds 3 could be important if the desirable catalyst was inexpensive and readily available. The treatment of 1,8-diaminonaphthalene 2 with various aldehydes and ketones 3in the presence of glacial acetic acid as a catalyst produced a series of new 2-substituted-2,3-dihydro$1 \mathrm{H}$-perimidine $4 \mathrm{a}-\mathrm{j}$ in high yield, as shown in Scheme 1. Cinnamaldehyde and various aromatic aldehydes bearing electronwithdrawing and electron-donating groups reacted with 1,8-diaminonaphthalene2 to give 2-substituted-2,3-dihydro- $1 \mathrm{H}$ perimidines $4 a-d$ in very good yields. Similarly, heteroaromatic aldehyde such as furfural afforded the product $4 \mathrm{e}$ in $84 \%$ yield, as shown in Table 1 . Since at room temperature-condition, the reactions were progressed smoothly and products were obtained in very good yields, and in high purity, the dipolar cyclization process of 1,8-diaminonaphthalene2 was extended for the preparation of five other new 2,3-dihydro- $1 \mathrm{H}$-perimidines $4 \mathrm{f}-\mathrm{j}$ using various aliphatic and aromatic ketones3. In general, the reaction of aliphatic ketones requires a longer time than aromatic ketones because the conjugating factor of the phenyl ring in aromatic ketones played a key role in affecting the rate of reaction. Herein, it is believed that the $1 \mathrm{H}$-perimidine ring formation in 2,3dihydro- $1 \mathrm{H}$-perimidines $4 a-j$ may proceed via a mechanistic pathway, which is shown in Scheme 2. Addition of an amino group 2 to the protonated carbonyl group of aldehydes and ketones 3leads to the formation of (8-amino-naphthalen-1ylamino)-phenyl-methanol (A) via standard nucleophilic addition. Although this is likely to be an equilibrium reaction, "hemiaminals" $(A)$ are expected to undergo rapid dehydration in the presence of acid to a highly reactive N8-benzylidenenaphthalene-1,8-diamine (B). Then the carbon of the imine system in (B) underwent 1,6-dipolar cyclization with the remaining amino group to afford 2,3dihydro-1H-perimidine (4a-j).

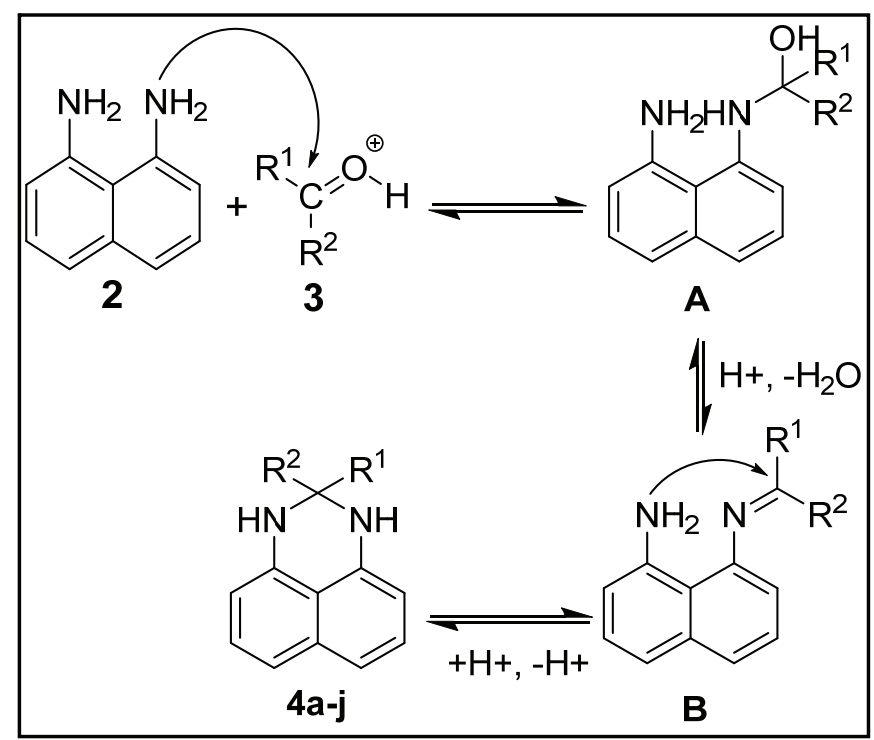

Scheme 2: Plausible mechanistic pathway for the formation of 2-substituted-2,3-dihydro$1 \mathrm{H}$-perimidine $(4 \mathrm{a}-\mathrm{j})$ 
The ${ }^{1} \mathrm{H}$-NMR spectral data of compound (4h) for example had supported the infrared finding by displaying a broad singlet signal at $4.2 \mathrm{ppm}$ due to the $\mathrm{NH}$ groups of the $1 \mathrm{H}$ perimidine ring, in addition; the spectrum has also revealed another singlet signal at $2.9 \mathrm{ppm}$ due to the methylene groups. Further verification for the formation of the $1 \mathrm{H}$-perimidine ring was attained from ${ }^{13} \mathrm{C}-\mathrm{NMR}$ spectrum, with the signals at 69 and $44 \mathrm{ppm}$ due to the carbon atom that attached to the nitrogen atoms of the $1 \mathrm{H}$-perimidine ring and the methylene groups respectively, and for our awareness the depicted signals in the aromatic region are in convenient with the number of carbon atoms of the naphthalene and phenyl rings, for example, compounds $4 a$, 4b, 4g, 4h, 4i and 4j showed 12,10,6,12,10 and 10 lines, respectively for different types of carbons in the aromatic region, as shown in Table 2 and 3.

\section{Antimicrobial activities}

Experiments were performed to evaluate the activities of the synthesized compounds against two species of bacteria $S$. aureus and E. coli. Anti-microbial study was assessed by measuring the minimum inhibitory zone (using disk agar diffusion method), and the results were represented in Table 4. The biological interest of perimidine derivatives were recorded in the literature. Therefore, the antibacterial study was done, and the activity was determined by the disc diffusion method at the concentration of $50 \mu \mathrm{g}$ per disk. All the synthesized used compounds were tested for their antibacterial activity against both bacteria $S$. aureus and $E$. coli. The amoxicillin, azithromycin, ciprofloxacin, and gentamicin were chosen as a standard antibacterial agent. Gentamicin and ciprofloxacin have a wide effect on protein synthesis in bacteria. Ciprofloxacin medication is used to treat a variety of bacterial infections. The synthesized compounds were more active against $E$. coli than the $S$. aureus. The compound $4 \mathrm{i}$ was moderately active against both the gram-positive and the gram-negative tested bacteria, whereas the most effective compounds of perimidine derivatives were $4 a, 4 c, 4 e$, and $4 j$, due to the presence of furan moiety (in case of compound $4 \mathrm{e}$ ) and the presence of double bond and the aromatic ring (in case of compound 4a) which increase the lipophilicity of the tested synthesized compounds and give the highest inhibition effect. While compounds (4b,4d, 4f,4g,4h and 4i) were showed moderate activity against $E$. coli. All the synthesized compounds were found to exhibit more activity than the standard drug gentamicin that has a wide effect on the $E$. coli and they showed more activity than the amoxicillin, azithromycin that have a wide effect on gram positive bacteria. The results showed the effect of substituents on the activity of perimidine derivatives against both bacteria walls. Bacteria cell walls contain peptidoglycan, lipopolysaccharide, lipoprotein, phospholipid, and protein. The increased activity may be attributed to the enhancement of lipophilicity due to incorporation of aromatic benzene ring and substituent $\mathrm{NO}_{2}$ and $\mathrm{OCH}_{3}$ groups at meta and para positions with the presence of perimidine moiety or $(\mathrm{OH})$; these compounds tend to be highly bound to protein, the more lipophilic compound, the greater binding. Table 5 investigates the percentage of the sensitivity of the bacteria species under the study, which was $0 \%$ for $S$. aureus, while the sensitivity of $E$. coli was $100 \%$.

\section{Anti-inflammatory activities}

As can be seen from Tables 6 and 7, only compound $4 \mathrm{~b}$ showed any appreciable activity ( $47 \%$ inhibition at $1000 \mathrm{nM})$ against COX II. This greater COX II selectivity is attributed to introducing larger substituents ( $\mathrm{COOH}$ replaced bychloro-benzene) to fit into the active site volume of $\mathrm{COX}$ II. ${ }^{18}$ Marnett et al. demonstrated similar results when they attempted to shift the enzyme selectivity of indomethacin from COX I to COX II while maintaining potency at the same level and reducing the unwanted side-effects at the same time. ${ }^{19}$ In their 
studies, they converted the non-selective NSAIDs to esters and amides in order to obtain selective COX II inhibitors. The acidic center of NSAIDs is crucial for their activities as they interact with the cationic site of the receptor; therefore, the more acidic, the better the inhibition. Based on this, the reason behind the reduced activity of the prepared derivatives $4 a-j$ against cox I (29-40\% inhibition) might be attributed to the fact that the perimidines are not acidic where as NSAIDs with carboxylic acid (such as naproxen 5, Figure 2) functionalities are. ${ }^{20-22}$ Naproxen 5 is a relatively simple molecule with a naphthyl scaffold, similar to compounds 4a-j. Moreover, it had been established by Zhang et al, when they did docking study for 19 triazole containing permidines, that the compounds could shrink the cavity space in the same manner as naproxen molecule could in the COX II binding pocket, thereby enhancing the interaction force. ${ }^{23}$ Additionally, the perimidine ring can interact with the upper right hydrogen bond donor, in a manner equivalent to that of the carbonyl group of naproxen acting as hydrogen bond acceptor. Therefore compound $4 \mathrm{~b}$ might had a stronger interaction with COX II. This resulted in a better inhibitory effect on COX II. ${ }^{23}$ (Figure 3).

\section{Conclusion}

A simple, efficient, and environmentally friendly approach and easy work-up has been used for the preparation of perimidines $4 a-j$ with a view to acquiring a good antibacterial activity. The antibacterial profile of all the synthesized compounds $4 a-j$, Table 4 revealed that the prepared 2-substituted-2,3-dihydro-1 $\mathrm{H}$ perimidine $4 a-j$ possessed significant antibacterial activity towards Escherichia coli microorganism and the highest activity was observed for compounds $(4 \mathrm{c}, 4 \mathrm{e}$, and $4 \mathrm{j}$ ), and they were more active than the standard drugs against both gram negative and gram positive bacteria. The synthesized compounds 4a-jwere effective against Gram negative bacteria because their cell walls contain a thin peptidoglycan



Figure 2: Naproxen structure.

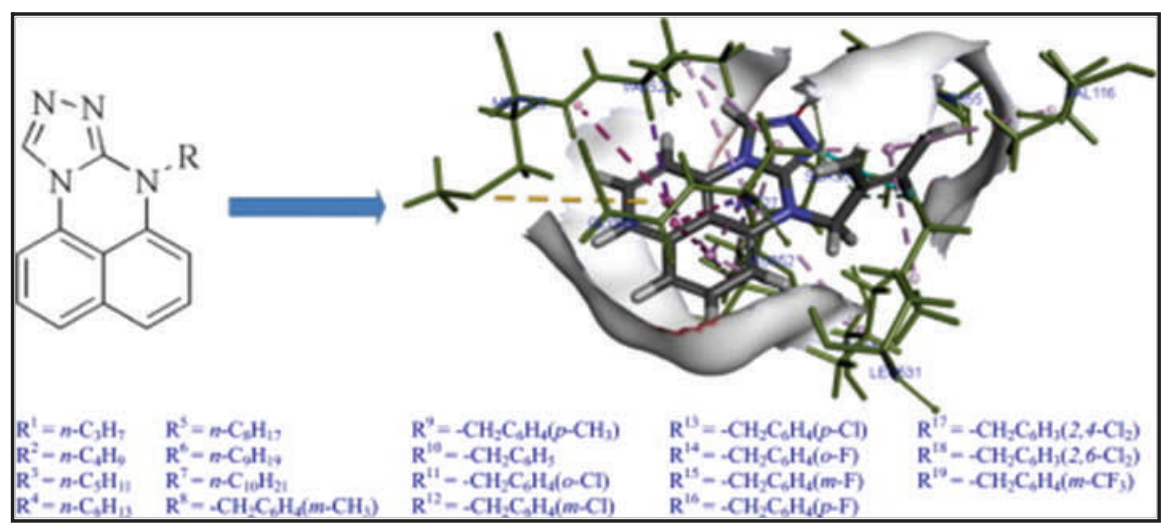

Figure 3: Triazole containing permidines tested by Zhang and his coworkers. ${ }^{23}$ 
layer (without techoic acids) that is surrounded by a thick plasma membrane. On the other hand, the compounds were inactive against Gram positive bacteria because of their thick peptidoglycan cell wall. In addition, the synthesized perimidine derivatives $4 a$-jwere evaluated for their anti -inflammatory activities using the Cayman's assay. Compound 4b showed the most potent anti-inflammatory activity with an inhibition rate of $47 \%$ at $1000 \mathrm{nM}$, which can be attributed to incorporating larger substituents to enable a better fit into the active site volume of COX II. However, naproxen5 showed around $88 \%$ and $66 \%$ inhibitory activity against COX I and COX II, respectively, due to a reduced interaction with the receptor. Accordingly, the perimidine scaffold is a promising candidate for finding safer antiinflammatory activity and greater COX II selectivity.

\section{Competing interests}

The authors declare no competing interests.

\section{References}

1. Mistry K, Desai K. Synthesis of novel heterocyclic 4-thiazolidinone derivatives and their antibacterial activity. J Chem 2004; 1(4):189-93.

2. Manojkumar P, Ravi T, Subbuchettiar G. Synthesis of coumarin heterocyclic derivatives with antioxidant activity and in vitro cytotoxic activity against tumour cells. Acta Pharma 2009; 59(2):159-70

3. Palekar VS, Damle AJ, Shukla SR. Synthesis and antibacterial activity of some novel bis-1,2,4-triazolo[3,4-b]-1,3,4-thiadiazoles and bis -4-thiazolidinone derivatives from terephthalic dihydrazide. Eur J Med Chem 2009; 44(12):5112 $-6$.

4. Arora P, Arora V, Lamba H, Wadhwa D. Importance of heterocyclic chemistry: A review. Int J Pharm Sci Res 2012; 3(9):2947.

5. Bassyouni FA, Abu-Bakr SM, Hegab KH, El-Eraky W, Ahmed A, Rehim MEA. Synthesis of new transition metal complexes of $1 \mathrm{H}$-perimidine derivatives having antimicrobial and antiinflammatory activities. Res Chem Intermed 2012; 38(7):1527-50.

6. Malladi S, Isloor AM, Isloor S, Akhila DS, Fun H-K. Synthesis, characterization and antibacterial activity of some new pyrazole based Schiff bases. Arab J of Chem 2013; 6(3):335-40.
7. Liu KC, Chen HH. Reaction of 2-hydrazinoperimidine with acetylacetone. J Heterocycl Chem 1984; 21(3):911-2.

8. Isikdag I, Incesu Z, Gülnaz D, Özkay Y. Cytotoxic Effects of Some Perimidine Derivatives on F2408 and 5Rp7 Cell Lines/Perimidin Türevlerinin F2408 ve 5Rp7 Hücre Hatlari Üzerine Sitotoksik Etkileri. FABAD J Pharm Sci 2008; 33(3):135.

9. Herbert JM, Woodgate PD, Denny WA. Potential antitumor agents. 53. Synthesis, DNA binding properties, and biological activity of perimidines designed as minimal DNA-intercalating agents. J Med Chem 1987; 30(11):2081-6.

10. Pozharskii AF, Dal'Nikovskaya V. Perimidines. Russ Chem Rev 1981; 50(9):816-35.

11. Davis R, Tamaoki N. Novel photochromic spiroheterocyclic molecules via oxidation of 1, 8-diaminonaphthalene. Organic lett 2005; 7(8):1461-4.

12. Kahveci B, Karaali N. Synthesis of new perimidine derivatives from the reaction of 1, 8-diaminonapthalene with iminoester hydrochlorides. J Chem Res 2013; 37(6).

13. Nikolaidis I, Favini-Stabile S, Dessen A. Resistance to antibiotics targeted to the bacterial cell wall. Protein Sci 2014; 23(3):243-59.

14. Helander I, Nurmiaho-Lassila E-L, Ahvenainen $\mathrm{R}$, Rhoades J, Roller S. Chitosan disrupts the barrier properties of the outer membrane of Gram -negative bacteria. Int J Food Microbiol 2001; 71(2-3):235-44.

15. Varsha G, Arun V, Robinson P, Sebastian M, Varghese D, Leeju $P$, et al. Two new fluorescent heterocyclic perimidines: first syntheses, crystal structure, and spectral characterization. Tetrahedron Lett 2010; 51(16):2174-7.

16. Salih KM, Azeez HJ. Synthesis, characterization and biological activity of 2-Aryl-2, 3-dihydro-1Hperimidine. Res Pharm Biotech 2014; 5(1):1-6.

17. Nile SH, Ko EY, Kim DH, Keum Y-S. Screening of ferulic acid related compounds as inhibitors of xanthine oxidase and cyclooxygenase- 2 with anti-inflammatory activity. Rev Bras Farmacogn 2016; 26(1):50-5.

18. Dannhardt G, Kiefer W. Cyclooxygenase inhibitors-current status and future prospects. Eur J Med Chem 2001; 36(2):109-26.

19. Kalgutkar AS, Crews BC, Saleh S, Prudhomme $D$, Marnett LJ. Indolyl esters and amides related to indomethacin are selective COX-2 inhibitors. Bioorg Med Chem 2005; 13(24):6810-22.

20. Flower RJ. The development of COX2 inhibitors. Nat Rev Drug Disc 2003; 2(3):179.

21. Hadjipavlou-Litina D. Quantitative structureactivity relationship (QSAR) studies on non steroidal anti-inflammatory drugs (NSAIDs). Curr Med Chem 2000; 7(4):375-88.

22. Abdou WM, Ganoub NA, Sabry E. Synthesis and quantitative structure-activity relationship study of substituted imidazophosphor ester based tetrazolo [1, 5-b] pyridazines as antinociceptive/ 
Synthesis and pharmacological profile of some .......

Zanco J. Med. Sci., Vol. 24, No. (1), April, 2020

https://doi.org/10.15218/zjms.2020.010

anti-inflammatory agents. Beilstein J Org Chem 2013; 9:1730.

23. Zhang $H J$, Wang $X Z$, Cao $Q$, Gong GH, Quan ZS. Design, synthesis, anti-inflammatory activity, and molecular docking studies of perimidine derivatives containing triazole. Bioorg Med Chem Lett 2017; 27(18):4409-14. 